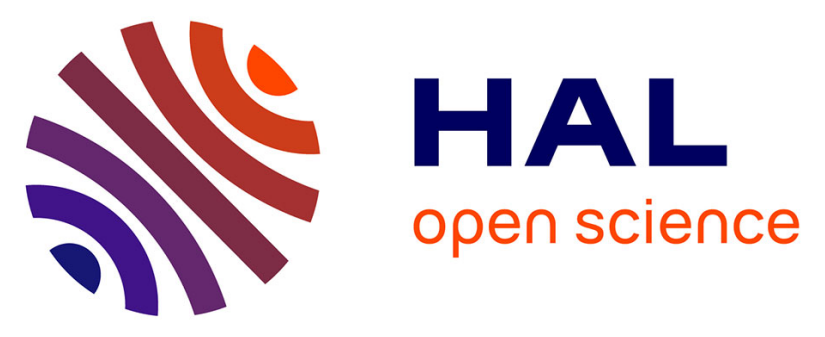

\title{
Unveiling TMP Process Water Potential As an Industrial Sourcing of Valuable Lignin-Carbohydrate Complexes toward Zero-Waste Biorefineries
}

Virginie Steinmetz, Maud Villain-Gambier, Armand Klem, François Gambier, Stéphane Dumarcay, Dominique Trebouet

\section{To cite this version:}

Virginie Steinmetz, Maud Villain-Gambier, Armand Klem, François Gambier, Stéphane Dumarcay, et al.. Unveiling TMP Process Water Potential As an Industrial Sourcing of Valuable LigninCarbohydrate Complexes toward Zero-Waste Biorefineries. ACS Sustainable Chemistry \& Engineering, 2019, 7 (6), pp.6390-6400. 10.1021/acssuschemeng.9b00181 . hal-02271749

\author{
HAL Id: hal-02271749 \\ https://hal.science/hal-02271749
}

Submitted on 11 Sep 2020

HAL is a multi-disciplinary open access archive for the deposit and dissemination of scientific research documents, whether they are published or not. The documents may come from teaching and research institutions in France or abroad, or from public or private research centers.
L'archive ouverte pluridisciplinaire HAL, est destinée au dépôt et à la diffusion de documents scientifiques de niveau recherche, publiés ou non, émanant des établissements d'enseignement et de recherche français ou étrangers, des laboratoires publics ou privés. 


\section{Unveiling TMP process water potential as an}

\section{industrial sourcing of valuable Lignin-Carbohydrate}

\section{Complexes towards zero-waste biorefineries}

Virginie STEINMETZ ${ }^{[a, b]}$, Maud VILLAIN-GAMBIER* ${ }^{[a]}$, Armand KLEM ${ }^{[c]}$, François

GAMBIER $^{[b]}$, Stéphane DUMARCAY ${ }^{[b]}$, Dominique TREBOUET $T^{[a]}$

[a] Laboratoire de Reconnaissance et Procédés de Séparation Moléculaire (RePSeM), Université de Strasbourg, Institut Pluridisciplinaire Hubert Curien (IPHC), UMR CNRS 7178, 25 rue Becquerel, 67087 Strasbourg Cedex 2, France

[b] Laboratoire d’Etudes et de Recherche sur le Matériau Bois, EA 4370 USC INRA, Boulevard des Aiguillettes, BP 70239, 54506 Vandoeuvre lès Nancy, France

[c] Norske Skog Golbey, Route Jean-Charles Pellerin, BP 109, 88194 Golbey, France

* Corresponding author email: maud.villain@unistra.fr, tel: +33(0)368852748

KEYWORDS: Lignin-Carbohydrate Complexes, lignin, galactoglucomannans, membrane filtration, biorefineries, SEC, 2D-NMR, thermomechanical process. 
ABSTRACT: The development of zero waste biorefineries is a promising yet challenging pathway towards a sustainable bioeconomy. Deep insights on the composition of biorefineries side streams along with the development of green technologies are mandatory to achieve such goal. In this paper, a sustainable pilote scale membrane process was used to recover valuable organic matter dissolved in the main side stream of a thermomechanical pulping (TMP) plant. A great number of analytical tools were combined to get an extensive characterisation of the generated fraction, including ICP-AES, HPIC-PAD, FTIR, SEC, ${ }^{13} \mathrm{C}$ and 2D HSQC NMR. The results revealed the presence of a considerable amount of native Lignin-Carbohydrate Complexes (LCCs) in the fraction representing $40 \%$ of the dry weight. The LCCs are composed of partially acetylated galactoglucomannans (GGM) covalently linked to low condensed and $\beta$ O-4 rich lignin through phenyl glycosidic bonds (25.5 bonds/100Ar rings) and characterized by a relatively low molecular weight around $7 \mathrm{kDa}$. Such complexes present an interesting potential for valorisation with unique properties resulting from the combination of their aromatic and sugar moieties. Different applications are discussed in regards to the generated data in this work as an industrial sourcing of LCC is reported.

\section{INTRODUCTION}

The development of a new bioeconomy implies the sustainable and optimised exploitation of bioresources through environmentally safe processes. In this context, efforts are made on the optimisation of biorefineries fluxes for the reduction of their carbon footprint. Thus, finding applications for all biomass constituents, including industrial coproducts, appears as a major concern. Thermomechanical pulping (TMP) is a high yield process retaining more than $90 \%$ of the wood biomass in the end product. ${ }^{1}$ The organic loss is dissolved and diluted in the process water representing the main side stream of TMP plants. Accumulation of dissolved and colloidal 
wood substances in the process water upon recirculation is known to cause impairments to the paper quality. ${ }^{2}$ Instead of discarding this side stream to waste water treatment plants, as it is currently the case, its valorisation for renewable materials or active biomolecules production can result in significant improvement of TMP plants profitability while greatly reducing the amount of generated wastes. ${ }^{3}$ Although the concentration of wood constituents in the process water is low (in the range of 1 g.L $\mathrm{L}^{-1}$ ), their potential for valorisation is considerable as the flow rate of process water in TMP is of several hundred cubic meters per hour.

Membrane filtration processes have proved their suitability as an energy-efficient separation technique for the recovery of substances at really low concentration. ${ }^{4-8}$ Membrane filtration is a clean and sustainable technology where the separation process is carried out solely on the basis of physical parameters, excluding the use of chemicals or additives. This results in an end product of high quality, and makes it easier to comply with the many stringent requirements from both consumers and public authorities. Another advantage of membrane filtration is that the recovered water can be reused in the mill to work on closed loop. As TMP plants are known to consume incredible amount of water in their process, this technology represents an opportunity to improve their environmental impact. By reducing the fresh water consumption and wastewater treatment cost, economic benefits also emerge from this process in addition to the new income from side stream valorisation.

The TMP process water has been extensively studied and its global composition is well documented. ${ }^{6,9-11}$ The main constituents recoverable for valorisation include hemicelluloses, lignin, fatty acids and phenolic extractives. The molecular weight (MW) distribution reported in TMP water process does not exceed $100 \mathrm{kDa}$ with a molecular weight around $20 \mathrm{kDa}$ for hemicelluloses and 1-10 kDa for lignin. ${ }^{12}$ Ultrafiltration using membrane cut-off of 1 and $5 \mathrm{kDa}$ 
has demonstrated its suitability to recover those macromolecules after a first clarification step, such as microfiltration. ${ }^{6,712}$ For a long time, lignin and hemicelluloses have been considered as two different and separated macromolecules. The interest was focused on hemicelluloses recovery supported by the fact that it is the major constituent dissolved in process water. However during the recovery and purification of hemicelluloses, systematic residual amounts of lignin were found in the fractions. ${ }^{6,7,12}$ In the same way, multiple selective extraction steps with low yields were required to remove the sugar contaminants while trying to isolate lignin. ${ }^{10}$ It's now well acknowledged that the physical separation of hemicelluloses and lignin is limited by the presence of covalent linkages between these two molecules. ${ }^{13,14}$ Only some part of the hemicelluloses and lignin can be recovered as pure fractions from the TMP process water underlining the presence of a third class of macromolecule called lignin carbohydrate complex (LCC).

LCCs are composite macromolecules understudied in comparison to lignin and hemicelluloses but they have been attracting more attention these past few years. The current knowledge on LCCs structures was mainly generated from studies on mild wood extraction, such as milled wood or Björkman extraction, to broaden the understanding of the wood fibers structural organisation in situ. ${ }^{15-18}$ Other part of the knowledge comes from studies on industrial pulp aiming to characterise the lignin carbohydrate linkages (LCLs) remaining after wood pretreatment in order to improve the delignification process. ${ }^{13,19}$ Some recent publications also focus on LCCs specific properties for industrial valorisation as a renewable resource. It was reported that their mechanical properties confer them a great potential for applications such as barrier film formation for sustainable food packaging or biocompatible hydrogel production as cells carrier in biomedicine. ${ }^{20,21}$ Biological properties have also been published such as anti- 
herpes and anti-HIV for pharmaceutic applications or anti-scavenging and anti-UV activities for cosmetic applications. ${ }^{22-24}$ Those works highlight the great potential of LCCs valorisation with unique applications resulting from the combination of lignin and hemicelluloses properties. However, until now, no commercialisation of LCCs has been reported.

A sustainable and economic sourcing of LCC is critical to ensure their industrial development. Revealing their recovery potential from residual feedstock, such as biorefinery effluents, seems to be the most promising path. In 2017, Narron et al. pointed out the presence of LCCs in the autohydrolysates of hardwood and non-wood biomass and brought deep characterisation insights. ${ }^{25}$ The same year, Al-Rudainy et al. proposed a process for LCCs recovery from spent sulphite liquor. ${ }^{26}$ Even if the presence of LCCs in TMP process water has been acknowledged for years while working on hemicelluloses valorisation, only indirect evidences are found in the literature. LCCs have never been quantified in TMP process water and no analytical data are available on their lignin part and LCLs involved. Strongly believing in the benefits that would bring a better understanding of LCC structural composition and recovery potential from TMP process water, this work combines a scalable and sustainable membrane process with advanced analytical tools, such as 2D NMR, for their isolation and characterisation. An approach for LCCs quantification is also proposed. Possible valorisation pathways are discussed in regard to the generated analytical data.

\section{EXPERIMENTAL SECTION}

\section{Materials}

The TMP process water used for this study came from Norske Skog Golbey industry (NSG), France. Spruce and fir mixed at a constant ratio are used as primary raw materials in the pulp mill. The dissolved wood constituents were recovered from $3 \mathrm{~m}^{3}$ of process water using pilote- 
scale flotation and filtration units (Figure 1). The overall process was designed based on previous published data to recover the dissolved constituents ranging from 1 to $100 \mathrm{kDa} \cdot{ }^{6,7}$ Flotation is required prior to membrane filtration in order to remove hydrophobic extractives and colloidal matters and prevent membrane fouling. This step was completed at Centre Technique du Papier (CTP, Grenoble, France). The accepted fraction went through further clarification by ultrafiltration (UF) on a $150 \mathrm{kDa}$ membrane and the organic matter of interest was then recovered in the retentate after ultra-filtration on a $1 \mathrm{kDa}$ membrane. A last nano-filtration (NF) step on a 300 Da membrane was employed to regenerate high quality grade industrial water which can be reinjected in the biorefinery process. The $1 \mathrm{kDa}$ retentate fraction was freeze-dried for preservation and characterisation purposes reaching $1.5 \mathrm{~kg}$ of dry matter. Freeze-drying was used for analytical purpose as it was considered as the most neutral drying process to avoid LCCs denaturation or degradation. For industrial scale-up, evapo-concentration and atomisation will be preferred and optimised. Detailed information on the membranes and operating conditions used in the process is given in supplementary data (Table S1).

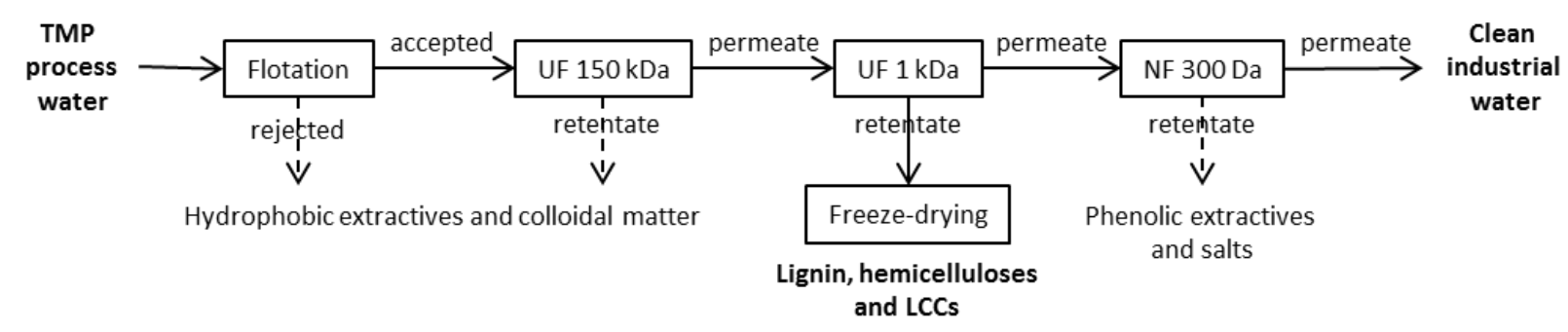

Figure 1. Schematic illustration of the overall process of TMP water treatment.

As internal analytical standard, Milled Wood Lignin (MWL) was extracted from a sample of NSG wood feedstock. Wood chips were ground to pass through a $0.5 \mathrm{~mm}$ sieve in a vibrating disc mill and Soxhlet-extracted twice with 2:1 (v/v) toluene:ethanol for $18 \mathrm{~h}$. The extractive-free sample was dried overnight at $103{ }^{\circ} \mathrm{C}$ and ground again in a rotary ball milling for $16 \mathrm{~h}$ at 320 rpm using two steel balls of $40 \mathrm{~mm}$. The ball milled powder was extracted twice with 96:4 (v/v) 
1,4-dioxane:water for $24 \mathrm{~h}$ in the dark at $450 \mathrm{rpm}$ and the MWL was recovered according to the method outlined by Brosse et al. and Holtman et al...27,28

\section{Elemental analyses}

The C, H, N and O elemental composition was determined with an elemental analyser (FLASH 2000 Thermofischer). Anions (Cl-, F- and Br-) were quantified by ionic chromatography (Dionex ICS-2000, AS19 Dionex column) after an overnight extraction in hot water assisted by ultrasonication and followed by filtration. The inorganic elemental composition was measured using inductively coupled plasma atomic emission spectroscopy (ICP-AES) (Variant 720 ES). The lignin was digested using $\mathrm{HNO}_{3} / \mathrm{HCl}$ in a microwaves reactor (Anton Paar Multiwave Eco).

\section{Organic composition}

Global organic composition of the freeze-dried powder was determined after acid hydrolysis following the NREL procedure with minor modifications. To sum up, $1.5 \mathrm{~mL}$ of $72 \%$ sulfuric acid were added to $0.175 \mathrm{~g}$ of powder (previously dried at $103{ }^{\circ} \mathrm{C}$ overnight) in $50 \mathrm{~mL}$ pressure tubes. The tubes were incubated $60 \mathrm{~min}$ at $30{ }^{\circ} \mathrm{C}$ in a water bath and samples stirred every 10 min. $42 \mathrm{~mL}$ of water were introduced to dilute the acid solutions to $4 \%$ and the tubes placed in an autoclave for $1 \mathrm{~h}$ of hydrolysis at $121^{\circ} \mathrm{C}$. The acid insoluble residues were gravimetrically determined after filtration through a glass fibers filter. The hydrolysates were analysed to quantify the acid-soluble lignin (ASL) by UV-VIS absorption spectroscopy at $205 \mathrm{~nm}$ and the monomeric reducing sugars by High Performance Anion Exchange Chromatography with Pulsed Amperometric Detection (HPAEC-PAD). A set of sugar recovery standards was prepared and used to correct the losses in quantification due to the degradation of monomeric sugars during the dilute acid hydrolysis. An extinction coefficient of $110 \mathrm{~L} \cdot \mathrm{g}^{-1} \cdot \mathrm{cm}^{-1}$ was used for ASL calculations. The acid-insoluble lignin (AIL) content was defined as the amount of ash-free 
Klason lignin (ash corresponding to the total of mineral matter quantified by HPIC and ICP). All measurements were carried out at least in triplicates.

\section{NMR experiments}

For all NMR analyses about $100 \mathrm{mg}$ of samples were dissolved in $0.5 \mathrm{~mL}$ of DMSO-d6. Spectra were recorded on a Bruker AVANCE III $400 \mathrm{MHz}$ spectrometer equipped with a BBFO probe $5 \mathrm{~mm}$ at $25{ }^{\circ} \mathrm{C}$. For quantitative ${ }^{13} \mathrm{C}$ NMR, an inverse gated decoupling sequence was used with a relaxation delay of $12 \mathrm{~s}$ and $13 \mathrm{~K}$ scans were acquired. 2D-HSQC NMR spectra were acquired with the following parameters: 128 transients, 16 dummy scans, relaxation delay of 1.9 s, 1024 data points in $\mathrm{F} 2\left({ }^{1} \mathrm{H}\right)$ dimension and 256 data points in $\mathrm{F} 1\left({ }^{13} \mathrm{C}\right)$. A coupling constant ${ }^{1} \mathrm{~J}_{\mathrm{C}-\mathrm{H}}$ of $145 \mathrm{~Hz}$ was used. The 2D data set was processed with MestreNova using a $90^{\circ}$ shifted square sine-bell apodization window. The data matrices were zero filled to 1024 points in both dimensions, baseline and phase corrections were applied in both dimensions. The central solvent (DMSO) peak was used as an internal chemical shift reference point $\left(\delta_{\mathrm{C}} / \delta_{\mathrm{H}} 40.1 / 2.51\right)$.

\section{Size Exclusion Chromatography}

The molar mass distribution of the lignin was determined using an aqueous SEC method on a Prominent Shimadzu HPLC equipped with a guard column Phenomenex Polysep GFC-P (7.8 x 35 mm) and two analytical columns Phenomenex Polysep P4000 (7.8 x 300 mm) and P3000 (7.8 x $300 \mathrm{~mm})$. A solution of sodium hydroxide $(\mathrm{NaOH})$ at $10 \mathrm{mM}$ was used as mobile phase. Samples were dissolved in the same solution at around $1 \mathrm{mg} \cdot \mathrm{mL}^{-1}$ and filtered through $0.45 \mu \mathrm{m}$ PTFE membrane filters. $20 \mu \mathrm{L}$ of sample solutions were injected. The separation was performed at $30{ }^{\circ} \mathrm{C}$ and $0.35 \mathrm{~mL} \cdot \mathrm{min}^{-1} \mathrm{NaOH}$ flow rate. An ultraviolet spectroscopy detector (UV) at 280 nm (Shimadzu SPD-20A) and a refractive index detector (RID, Shimadzu RID-20A) were used for detection. A calibration curve was obtained using a KIT of 8 pullulan standards (Agilent 
PL2090-0101) with molar mass ranging from 667 to 344000 Da. Measurements were carried out in triplicate.

\section{Hot water partition}

$1 \mathrm{~g}$ of freeze dried powder was extracted in $10 \mathrm{~mL}$ of deionised water at $80{ }^{\circ} \mathrm{C}$ for $4 \mathrm{~h}$. After filtration, on a pre-tared glass fibers filter, the solid residue was dried overnight at $103{ }^{\circ} \mathrm{C}$, gravimetrically quantified and analysed by SEC and FTIR methods while the supernatant was filled up to $50 \mathrm{~mL}$, analysed by spectrophotometry at $205 \mathrm{~nm}$ and SEC method. The schematic distribution of lignin, hemicelluloses and LCCs is presented in Figure 2. Measurements were done in triplicates.

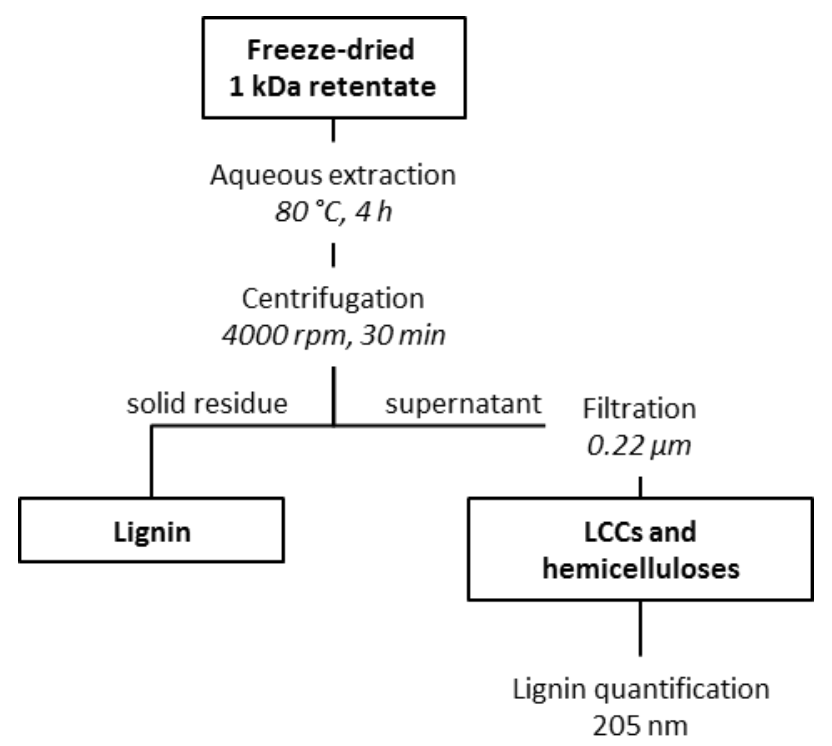

Figure 2. Distribution of lignin, hemicelluloses and LCCs upon water partition.

\section{FTIR spectroscopy}

FTIR spectra were acquired by Attenuated Total Reflectance (ATR) through a diamond cell on a Nicolet 6700. All spectra were recorded at a spectral resolution of $4 \mathrm{~cm}^{-1}$ and 16 scans were taken per sample in the range of 4000-650 $\mathrm{cm}^{-1}$. Omnic software was used for acquisition while Spectrum (Perkin Elmer) v10.5.1 was employed for data processing. 


\section{RESULTS AND DISCUSSION}

TMP fraction composition. Series of clarification and filtration steps were successfully applied at a pilote-scale for the treatment of $3 \mathrm{~m}^{3}$ of TMP process water allowing the recovery of dissolved wood constituents on one hand and the regeneration of clean industrial water on the other. The composition of the dry matter isolated and concentrated in the $1 \mathrm{kDa}$ retentate is detailed in Table 1 . The retentate is mainly composed of sugars and aromatic derivatives accounting for 59 and $23 \%$ of the dry matter respectively. A non-negligible amount of ash (7.7 \%) is also retained in the fraction. Elemental analysis showed that sulfur, calcium, sodium, potassium and magnesium are the main inorganic constituents in descending order (Table S2). As suggested by this composition, the industrial water used in the TMP process is suspected to be the main source of inorganic matter. Although free ash should pass through the $1 \mathrm{kDa}$ membrane, the retention observed is in the range of what is commonly found in TMP ultrafiltration fractions. ${ }^{5,6}$ Apart from sugars, aromatics and ash, the presence of lipophilic substances was confirmed by pyrolysis gas chromatography (Figure S1). The TMP fraction is also expected to contain some organic acids. These components were not quantified but are accounted for in “others” (Table 1).

Considering the relative abundance of sugars monomers, mannose units represent $62 \%$ of the total polysaccharides content followed by glucose and galactose units representing respectively 20 and $13 \%$. Only really small amount of arabinose and xylose were detected. This distribution indicates that almost exclusively galactoglucomannans (GGM) are recovered in the $1 \mathrm{kDa}$ retentate with a Man:Glc:Gal ratio of 3.1:1:0.6. Such composition was expected as GGM is the main hemicellulose encountered in softwood and the most sensitive to hydrolysis. Harder TMP 
conditions, e.g. higher temperature, are required for the extraction of arabinoglucuronoxylans, the second main hemicelluloses in softwood. ${ }^{29}$ Their absence is an indication of the mildness of the process. Those results are in line with other previous works on TMP process water using Norway spruce as feedstock. $5,6,9,12$

Table 1. Global composition of the dry weight recovered in the $1 \mathrm{kDa}$ retentate.

\begin{tabular}{|c|c|c|c|c|}
\hline & & \multirow[b]{2}{*}{ Dry wt\% } & \multirow[b]{2}{*}{1 kDa retentate } & \multirow[b]{2}{*}{ SD } \\
\hline & & & & \\
\hline Inorganics & Ash & & 7.7 & \pm 0.2 \\
\hline \multirow[t]{14}{*}{ Organics } & Sugars & Fucose & nd & nd \\
\hline & & Rhamnose & 0.06 & \pm 0.04 \\
\hline & & Arabinose & 1.00 & \pm 0.1 \\
\hline & & Galactose & 7.52 & \pm 0.44 \\
\hline & & Glucose & 11.77 & \pm 0.65 \\
\hline & & Xylose & 0.37 & \pm 0.04 \\
\hline & & Mannose & 36.33 & \pm 1.17 \\
\hline & & Galacturonic acid & 1.70 & \pm 0.52 \\
\hline & & Glucuronic acid & 0.28 & \pm 0.10 \\
\hline & & Sum & 59.0 & \pm 2.6 \\
\hline & Aromatics & Acid insoluble lignin & 15.7 & \pm 0.6 \\
\hline & & Acid soluble lignin & 7.5 & \pm 0.2 \\
\hline & & Sum & 23.2 & \pm 0.8 \\
\hline & Others & & 10.1 & \pm 3.6 \\
\hline
\end{tabular}

The composition detailed in Table 1 gives valuable but still incomplete information on the organic matter isolated by ultra-filtration. While considering the presence of LCCs as a third class of macromolecules, in addition to lignin and hemicelluloses, deeper characterization of this 
fraction is needed to define the repartition of sugars and aromatics between lignin, GGM and LCCs.

Lignin, GGM and LCCs repartition. The amount of GGM in the $1 \mathrm{kDa}$ retentate was estimated using the data generated by Oinonen et al. as both the origin and global composition of their retentate are really closed to the one in this work (Table S3). ${ }^{5}$ In their experiments, a laccase treatment was used to polymerise the relatively low molecular weight (LMW) LCCङ ( $15 \mathrm{kDa}$ ) into higher molecular weight (HMW) polymers $(60 \mathrm{kDa})$ and these latter were then recovered by ultrafiltration on a $30 \mathrm{kDa}$ membrane. A schematic representation of their process is given in Figure 3. As a result, the GGM, which were not affected by the laccase treatment, were physically separated from the LCCs allowing their quantification in the permeate fraction. According to their mass repartition and sugar analyses, $60 \%$ of the total sugars quantified in their $1 \mathrm{kDa}$ retentate were part of GGM and thus recovered in the permeate while the others 40 \% were involved in LCCs and quantified in the retentate. By transposing their quantification, it is possible to estimate that the GGM content in the present work accounts for $35 \%$ of the dry matter in the retentate.

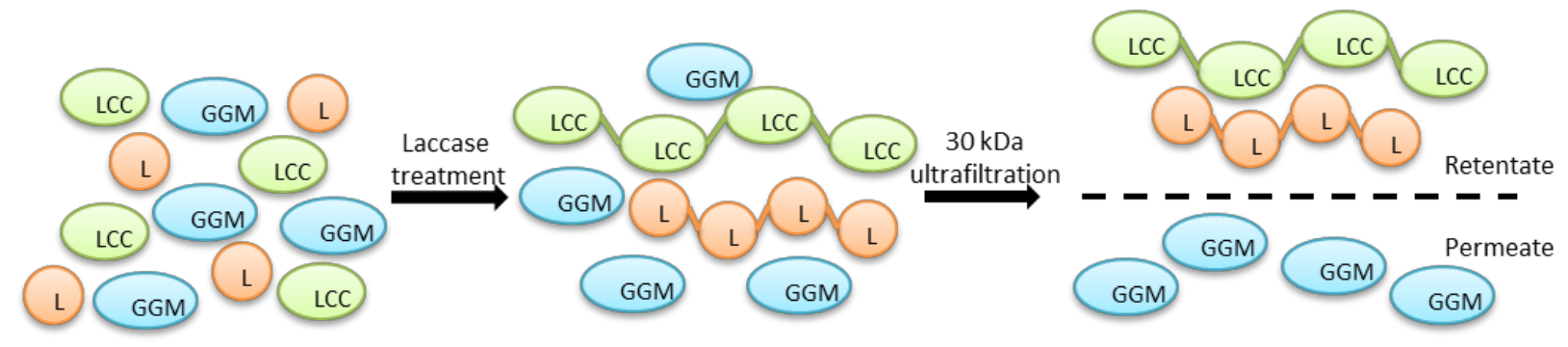


Figure 3. Schematic representation of the isolation process of GGM from the $1 \mathrm{kDa}$ retentate detailed in Oinonen et al. paper; L: lignin; GGM: galactoglucomannan; LCC: lignincarbohydrate complex.

As laccase treatment allows the polymerisation of LCCs through their phenolic moieties, not only LCCs but also the lignin was condensed as HMW polymers in Oinonen et al. work (Figure 3). In fact, it's accurate to say that all hemicelluloses involved in HMW polymer are covalently linked to lignin but not that all HMW lignin are covalently linked to hemicelluloses. Therefore, estimation of lignin content is not possible using this method.

In order to quantify the lignin in our fraction, an aqueous extraction of the freeze dried $1 \mathrm{kDa}$ retentate was conducted for $4 \mathrm{~h}$ at $80^{\circ} \mathrm{C}$. Those conditions were selected as they allow the solubilisation of GGM while lignin is known to be insoluble in water. ${ }^{30}$ It was also previously demonstrated in the literature that LCCs can be recovered from wood hot water extract. ${ }^{15}$ Thus, assuming that LCCs solubility would be driven by their carbohydrate moiety, the GGM and LCCs were expected to be dissolved in the supernatant while lignin were expected to be left alone in the solid residue allowing its quantification.

FTIR spectrum of the solid residue after hot water extraction is presented in Figure 4 and compared to the $1 \mathrm{kDa}$ retentate and MWL as references. The signals were assigned based on the literature. ${ }^{21,31,32}$ The absence of sugars in the solid residue is clearly demonstrated with the marked reduction of the broad $\mathrm{OH}$ bands at $3390 \mathrm{~cm}^{-1}$ and $1027 \mathrm{~cm}^{-1}$ as well as the disappearance of the specific hemicelluloses signal at $1728 \mathrm{~cm}^{-1}$. The spectrum of the solid residue perfectly matches the one of MWL. The specific signals of aromatic skeletal vibration are well defined at 1600, 1510 and $1454 \mathrm{~cm}^{-1}$. Only one significant difference was pointed out with the presence of an additional peak in the solid residue spectrum at $1758 \mathrm{~cm}^{-1}$. This peak was 
assigned to the carbonyl groups of phenyl esters. ${ }^{33,34}$ As this signal was not present in the initial retentate, the explanation proposed is that esterification reactions occurred during the extraction between lignin phenolic end groups and acetyl groups coming from partial deacetylation of GGM. Taken together, these observations confirmed that only lignin was left in the residue after hot water extraction and that LCCs were solubilised in the supernatant. Quantification of the lignin content by this method is then accurate.

After hot water extraction, $31 \%$ of the total aromatic content were recovered in the solid residue and assigned to lignin while $69 \%$ were solubilised in the supernatant and attributed to LCCs. Thus, regarding the composition of the $1 \mathrm{kDa}$ retentate, lignin accounts for $7 \%$ of the total dry matter among the $23 \%$ of aromatics. Another interesting conclusion of this experiment is also that LCCs is likely to present the same properties as GGM in terms of solubility. This information is of primary importance while considering further industrial development and formulation of LCCs.

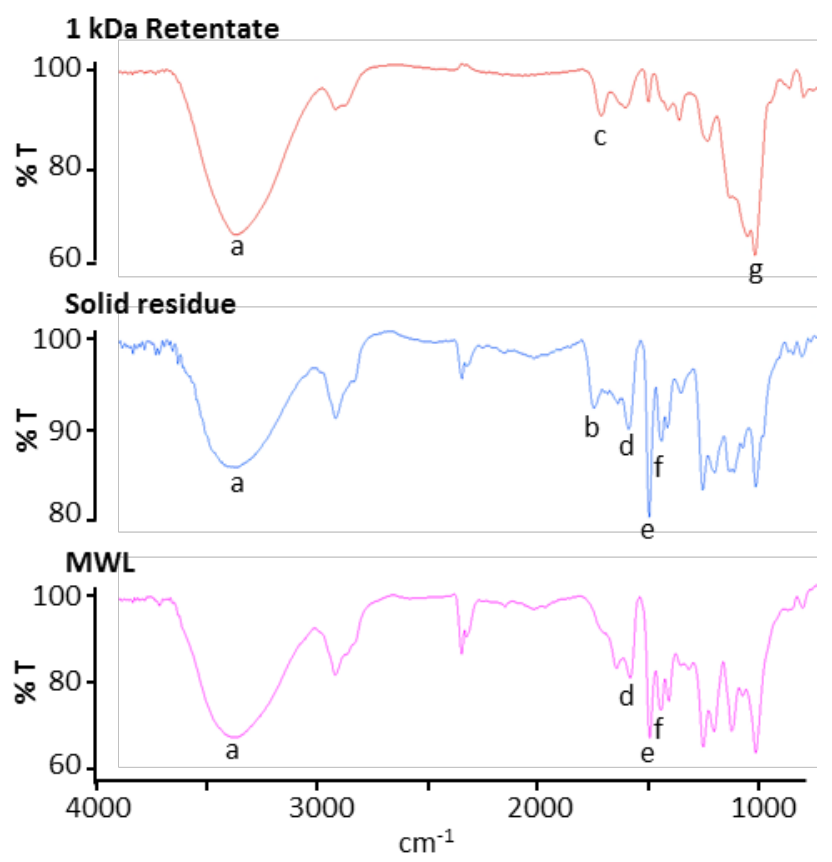


Figure 4. FTIR spectra of the $1 \mathrm{kDa}$ retentate (up), the solid residue after hot water extraction (middle) and the MWL (down). Signal assignment: a- hydroxyl groups $\left(3390 \mathrm{~cm}^{-1}\right)$; b- carbonyl groups of phenyl esters $\left(1758 \mathrm{~cm}^{-1}\right)$; c- carbonyl groups of hemicelluloses acetyl moieties (1728 $\mathrm{cm}^{-1}$ ); d-e-f- aromatic skeletal vibration (1600, 1510 and $\left.1454 \mathrm{~cm}^{-1}\right)$; g- primary alcohols (1027 $\left.\mathrm{cm}^{-1}\right)$.

The LCC content was calculated as the sum of the remaining sugars and aromatics in the fraction. Summarizing those results, the repartition of the organic matter between GGM, lignin, and LCCs is represented in Figure 5. $40 \%$ of the dry matter recovered in the $1 \mathrm{kDa}$ retentate correspond to LCCs. Presenting this way, the potential of TMP process water as an industrial sourcing of LCCs is highlighted, opening new economical markets for those biorefineries.

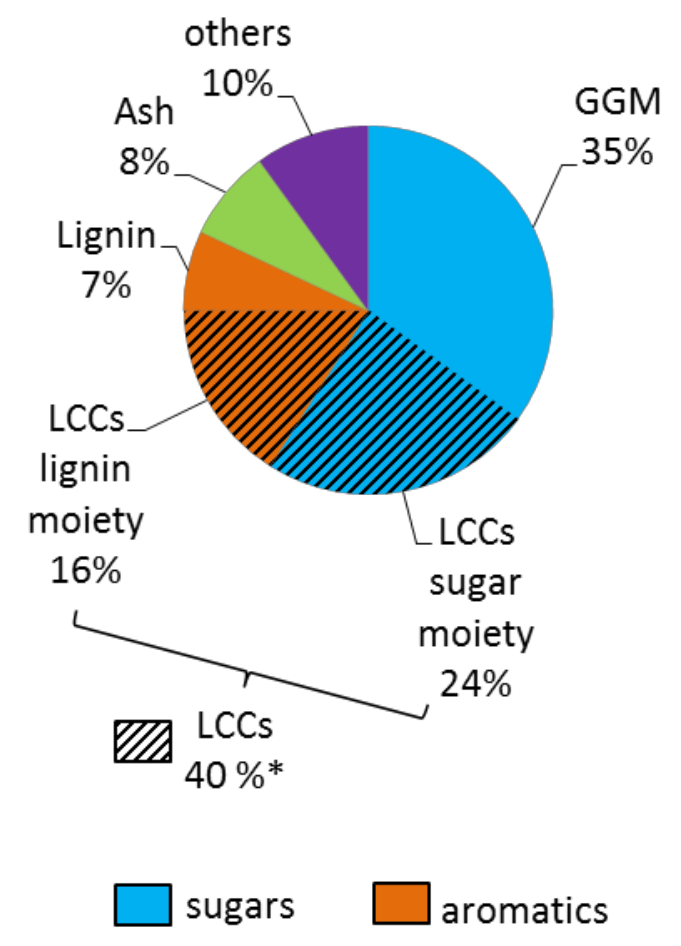


Figure 5. Dry matter composition of the $1 \mathrm{kDa}$ retentate with the contribution of GGM, lignin and LCCs. * Partly estimated on the basis of published data. ${ }^{5}$

Better knowledge of their structure would lead to better understanding of the mechanisms involved in their reactivity and suitable valorisation pathways. In that sense, the second part of this work focuses on LCC structural characterisation. The polysaccharidic part involved in LCCs is quite well defined as several researches were conducted on the hemicelluloses recovered from TMP process water. ${ }^{9,30,35,36}$ However, the same statement does not apply to their aromatic part. In an attempt to bring new data, accurate and advanced methods such as 2D-NMR were employed to get new insights on the lignin part involved in LCCs and the lignin carbohydrate linkages.

LCCs structural characterisation by NMR. The 2D-HSQC NMR was employed to identify the LCLs and lignin interunit linkages (LILs) in LCCs. The structures depicted through this method are presented in Figure 6. Assignments of the cross peak signals were made according to reputable publications (Table S4). ${ }^{15,16,37,38}$ Quantitative ${ }^{13} \mathrm{C}$ NMR was combined to 2D-HSQC study for the quantification of the different lignin and LCC linkages giving further information on the lignin condensation state. Currently, milled wood extraction is considered as the mildest wood extraction protocol at a lab-scale. Therefore, Björkman MWL and LCCs are considered as the most native structures isolated from wood and used as references reflecting the wood composition in situ. Thus, MWL was extracted from the wood feedstock used in the TMP plant and serves as internal standard in this work.

The 2D-HSQC NMR spectra of MWL and $1 \mathrm{kDa}$ retentate are displayed in Figure 7. As expected for softwood lignin, only $\mathrm{G}$ and $\mathrm{H}$ unit signals are detected in the aromatic region $\left(\delta_{\mathrm{C}} / \delta_{\mathrm{H}} 105-155 / 6-8\right)$ of the MWL spectrum (Figure $\left.7 \mathrm{~A}\right)$. Specific signals from oxidized end- 
structures of lignin are also present, probably resulting from the fragmentation of aryl ether linkages during the milling. ${ }^{15}$ The majority of the signals in the aliphatic region $\left(\delta_{\mathrm{C}} / \delta_{\mathrm{H}} 50\right.$ 105/2.5-6.5) is attributed to LILs (Figure 7C). Aryl ether, phenylcoumaran, resinol and dibenzodioxocin linkage signals are discernible on the spectrum. No carbohydrate or LCL signals are depicted indicating the high purity of this standard (Figure 7C).

In comparison, the TMP process allowed only the extraction of a very specific fraction of softwood lignin exclusively composed of $\mathrm{G}$ units (Figure 7B) mainly linked through labile $\beta$-O-4 aryl ether bonds (Figure 7D). Weak signals resulting from the $\mathrm{C}_{\alpha}-\mathrm{H}_{\alpha}$ and $\mathrm{C}_{\beta}-\mathrm{H}_{\beta}$ of phenylcoumaran linkages are also detected but resinol and dibenzodioxocin signals are totally absent in the spectrum. In agreement with the compositional analysis of the $1 \mathrm{kDa}$ retentate, the anomeric carbon signals from hemicelluloses detected in the aliphatic region are attributed to mannose, glucose and galactose units. The two cross peak signals at $\delta_{\mathrm{C}} / \delta_{\mathrm{H}} 71.2 / 5.26$ and 73.9/4.83 ppm indicate that the hydroxyl groups on carbon 2 and 3 of mannose units are partially acetylated. The presence of acetyl groups has been reported in the literature on native GGM and is also an evidence of the mildness of the TMP process. Among the three main LCLs currently observed in softwood (benzyl ether, gamma ester and phenyl glycoside), only phenyl glycosidic bond signals are detected. Working on the fractionation of softwood extract, Giummarella et al. reported that benzyl ether linkages were mainly involved in xylan rich LCCs while phenyl glycosidic bonds were associated to GGM-lignin complexes. ${ }^{15}$ As our fraction is purely composed of GGM and only phenyl glycosidic bonds are detected by 2D-HSQC NMR, our results are in line with their observation supporting this preferential distribution in softwood. 


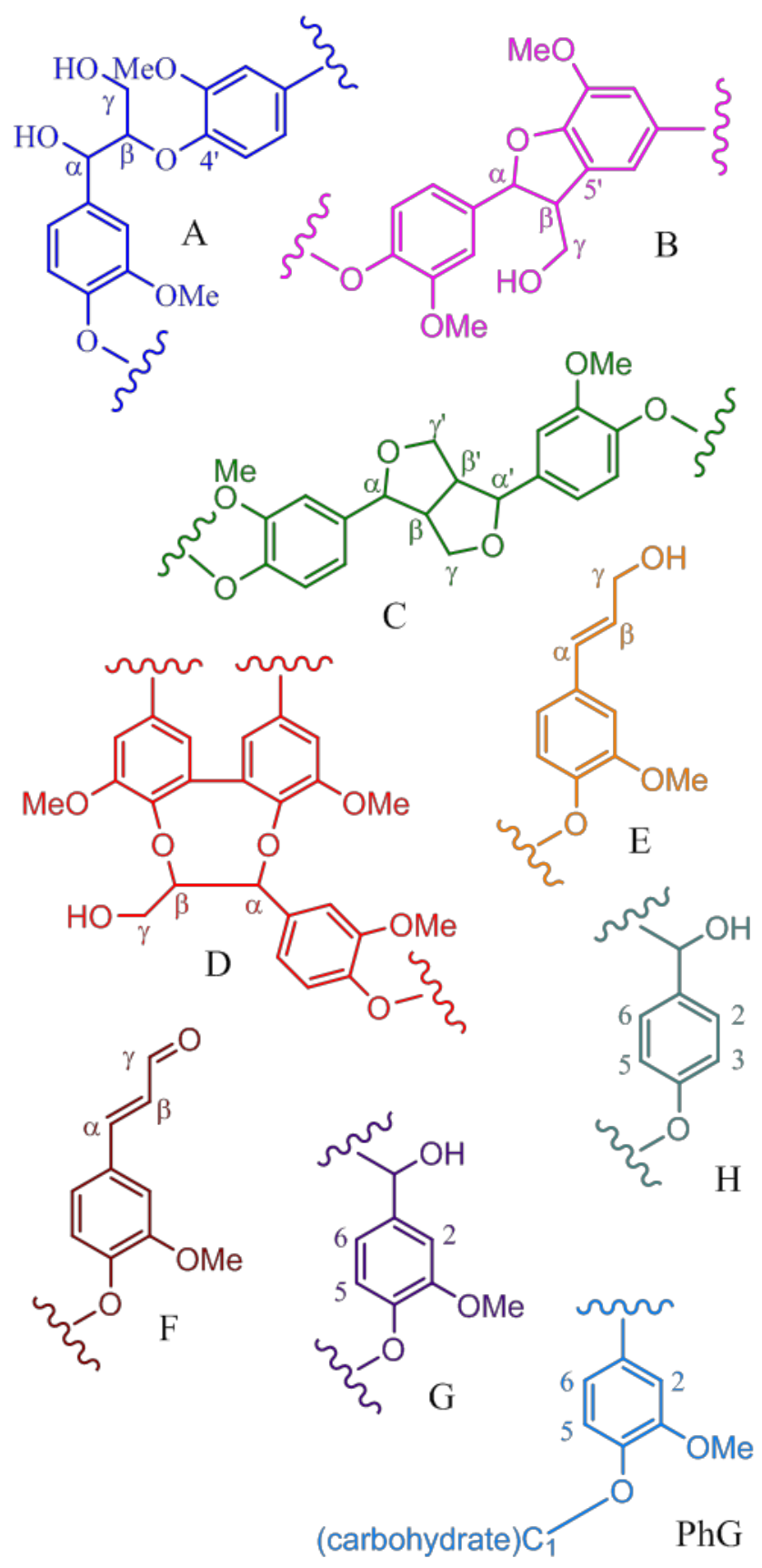

Figure 6. Main lignin and LCC structures identified and quantified by NMR spectroscopy: (A) $\beta$-O-4' aryl ether (B) $\beta-5$ ' phenylcoumaran (C) $\beta-\beta$ ' resinol and (D) dibenzodioxocin (DBDO) lignin interunit linkages; (E) cinnamyl alcohol and (F) cinnamaldehyde type lignin structures; (G) guaiacyl and (H) p-hydroxyphenyl lignin units; (PhG) phenyl glycoside LCC linkage. 

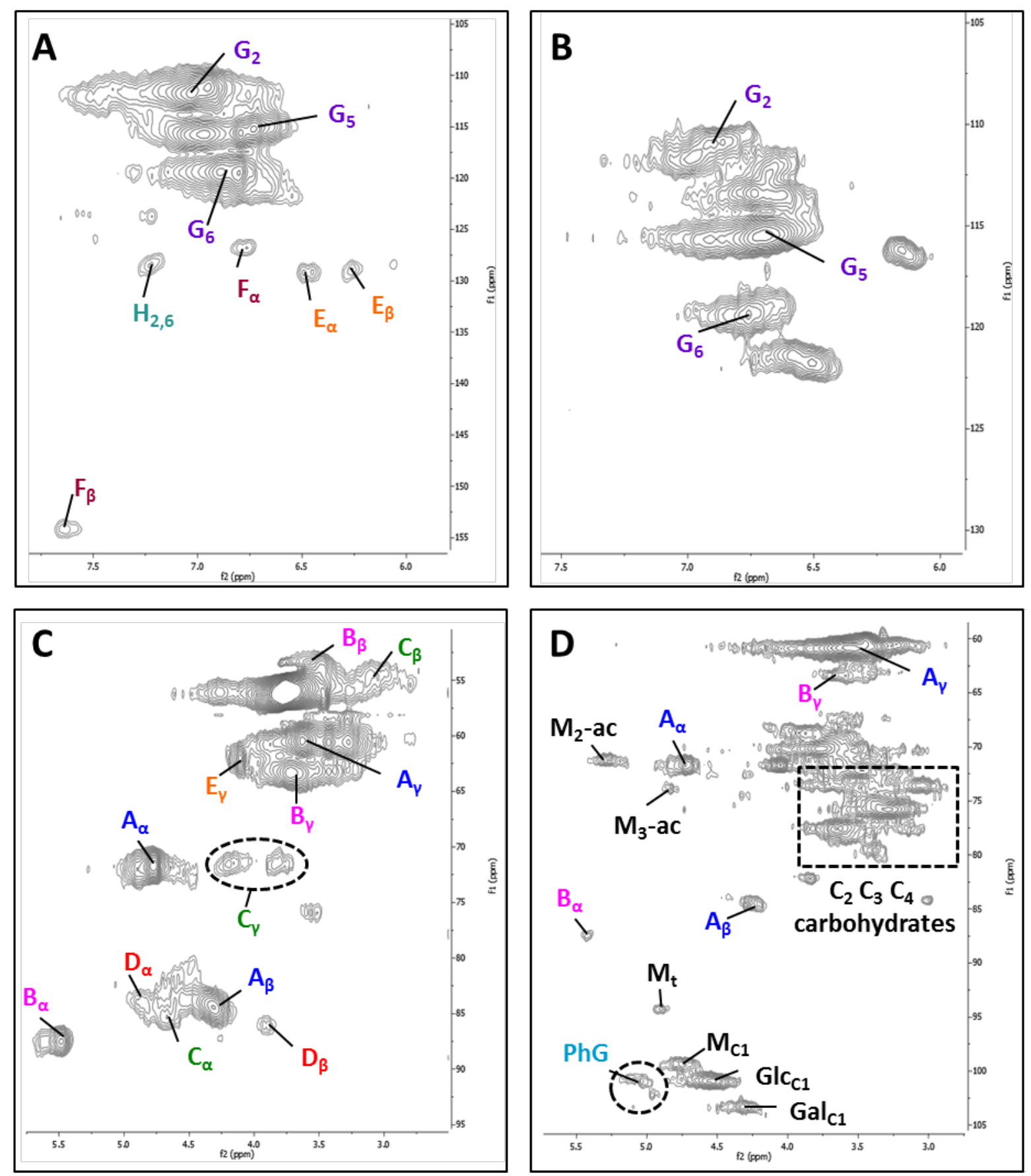

Figure 7. 2D-HSQC aromatic (A and B) and aliphatic (C and D) regions from the spectra of MWL (left) and $1 \mathrm{kDa}$ retentate (right). Sugars from hemicelluloses are depicted in the anomeric region of the $1 \mathrm{kDa}$ retentate: $\mathrm{M}=$ mannose, Glc=glucose and $\mathrm{Gal}=$ galactose, $\mathrm{t}$ subscript indicates the terminal reducing end, -ac subscript stands for acetylated carbon. 


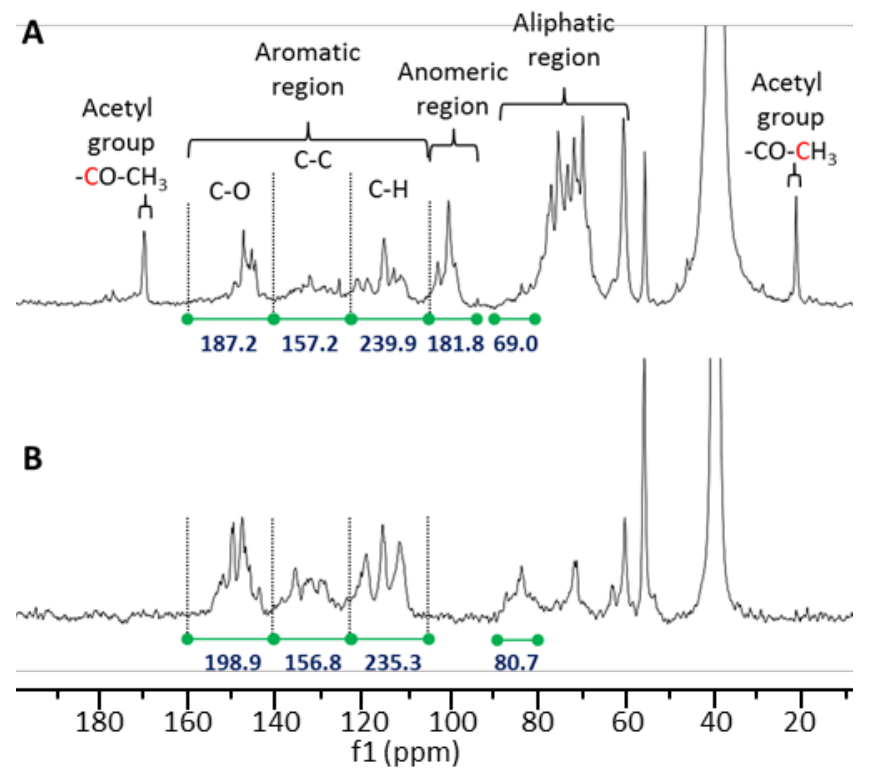

Figure 8. ${ }^{13} \mathrm{C}$ NMR spectra of the freeze-dried $1 \mathrm{kDa}$ retentate (A) and the MWL (B) with integration values (in blue) of different types of signal regions (in green); C-O: oxygenated carbons, C-C: condensed carbons and C-H: protonated carbons.

Quantitative ${ }^{13} \mathrm{C}$ NMR spectra of the $1 \mathrm{kDa}$ retentate and the MWL are shown in Figure 8. The main differences between the two spectra arise from the presence of hemicelluloses in the retentate. The signals at 21 and $170 \mathrm{ppm}$ are attributed to the acetyl groups attached to the $\mathrm{C}_{2}$ and $\mathrm{C}_{3}$ of GGM while the important difference in the aliphatic region is due to the GGM carbons themselves. Additional peaks are also detected between 94 and 105 ppm corresponding to the anomeric carbons of GGM. For quantification of the lignin and LCC linkages, the aromatic regions (105-160 ppm) were integrated and normalised to 600 resulting that the integral values of the other regions in the spectra are expressed per 100 aromatic rings. Those integrals were used as internal standard to convert the relative signals elucidated by $2 \mathrm{D}-\mathrm{HSQC}$ into ${ }^{13} \mathrm{C}$ based 
number per aromatic rings ( $\left.n^{\circ} / 100 a r\right)$ as previously reported in the literature. ${ }^{17,25,38}$ The anomeric region (94-105 ppm) was used as internal standard for phenyl glycoside quantification while a cluster at 80-90 ppm was used for LILs. Calculations were done using the following equations (1) and (2):

$$
\begin{aligned}
\frac{P h G}{100 a r} & =600 * \frac{2 D_{P h G}}{2 D_{(105-94 ; 5.5-4)}} * \frac{13 C_{(105-94)}}{13 C_{(160-105)}} \\
\frac{L I L}{100 a r} & =600 * \frac{2 D_{L I L}}{2 D_{(90-80 ; 6-2.5)}} * \frac{13 C_{(90-80)}}{13 C_{(160-105)}}
\end{aligned}
$$

For LILs, the integral values of the signals associated to $\mathrm{C}_{\alpha}-\mathrm{H}_{\alpha}$ in 2D-HSQC NMR were used in the equation to avoid possible interferences or overlapping. ${ }^{25,37}$ The quantification results are summarised in Table 2 and compared to published data.

The quantitative analysis of the inter-unit linkages in MWL is in agreement with those reported for spruce MWL in the literature. ${ }^{15,17,38}$ The total amount of LCLs per 100 aromatic rings quantified in the retentate is significantly higher than other reported data on LCCs isolated from different feedstocks (25 LCLs/100ar against 10-15 LCLs /100Ar respectively). ${ }^{16,25}$ As only mannan rich LCCs were isolated in the fraction, this result seems to highlight a specific high branching frequency between lignin and GGM. Recently, the fourth main industrial sourcing of lignin from biorefineries side streams were deeply characterised by Constant et al. and reported as highly condensed lignins with low $\beta-\mathrm{O}-4$ linkages content. ${ }^{37}$ In comparison, the aryl ether content of the lignin recovered in the $1 \mathrm{kDa}$ retentate is significantly higher and equivalent to the MWL content. 
Table 2. Quantification of the lignin interunit and lignin carbohydrate linkages (n/100ar).

\begin{tabular}{|c|c|c|c|c|c|c|c|c|c|c|}
\hline & \multirow{2}{*}{$\begin{array}{l}1 \mathrm{kDa} \\
\text { retentate } \\
\text { This work }\end{array}$} & \multicolumn{2}{|c|}{ MWL (spruce) } & \multicolumn{3}{|c|}{ LCCs } & \multicolumn{4}{|c|}{ Technical lignins ${ }^{37}$} \\
\hline & & $\begin{array}{l}\text { This } \\
\text { work }\end{array}$ & $\underset{15,17,38}{\text { literature }}$ & $\begin{array}{c}\text { Soft } \\
\text { wood } \\
16\end{array}$ & $\begin{array}{l}\text { Non- } \\
\text { wood } \\
25\end{array}$ & $\begin{array}{l}\text { hard } \\
\text { wood } \\
25\end{array}$ & $\begin{array}{c}\text { Indulin } \\
\text { Kraft }\end{array}$ & $\begin{array}{l}\text { Soda } \\
\text { P1000 }\end{array}$ & Alcell & $\begin{array}{c}\text { Organo } \\
\text {-solv } \\
\text { Spruce }\end{array}$ \\
\hline $\begin{array}{l}\beta-O-4^{\prime} \\
\text { (A) }\end{array}$ & 36.6 & 37.9 & $36-48$ & 22.4 & 13.4 & 33.6 & 6.1 & 3.4 & 5.3 & 0 \\
\hline$\beta-5^{\prime}(\mathrm{B})$ & 4.1 & 13.7 & $9-14.6$ & 5.1 & 0.7 & 1.5 & 0.3 & 0 & 0.8 & 3.3 \\
\hline$\beta-\beta^{\prime}(\mathrm{C})$ & nd & 7.3 & $3-3.7$ & 1.7 & 0.3 & 2.8 & 1.0 & 0.7 & 2.8 & 0.2 \\
\hline $\begin{array}{l}\text { DBDO } \\
\text { (D) }\end{array}$ & nd & 3.2 & & & 8.4 & nd & & & & \\
\hline PhG & 25.5 & nd & $0-4.1$ & 6.8 & 3.8 & 0.6 & & & & \\
\hline $\mathrm{BE}$ & nd & nd & & 4.3 & 0.5 & 2.0 & & & & \\
\hline$\gamma E$ & nd & nd & & 4.5 & 5.2 & 7.6 & & & & \\
\hline $\begin{array}{l}\text { Total } \\
\text { LCLs }\end{array}$ & 25.5 & & & 15.6 & 9.5 & 10.2 & & & & \\
\hline
\end{tabular}

Nd: not detected; PhG: phenyl glycoside; BE: benzyl ether; $\gamma \mathrm{E}$ : gamma ester; LCLs: Lignin Carbohydrate Linkages.

The mildness of the TMP process was already underlined by the presence of acetyl groups on the hemicelluloses as in native structures and this result reinforces the statement by pointing out that the TMP process allows the solubilisation of wood constituents while preserving their labile structures at least as well as milled wood extraction. In this sense, the wood constituents dissolved in the process water can be considered as native structures and their characterisation provides valuable knowledge to build up on the comprehension of the complex wood fibers organisation in situ. Even if the TMP process has always been considered and referred to as a mild process in the literature, it's the first time that quantitative evidence is generated with a direct comparison to milled wood extraction. The valorisation of the TMP side stream provides 
an industrial sourcing of wood model compounds which can be useful for fundamental research domains such as phytochemistry.

Information about the lignin condensation degree can also be deduced from the quantitative ${ }^{13} \mathrm{C}$ NMR study as previously reported. ${ }^{27}$ The aromatic region of the spectra was divided into three clusters according to the literature and 2D-HSQC spectra (Table S5). The condensation degree is calculated as the ratio of the condensed aromatic integral value on the protonated aromatic one (Figure 8). The lignin isolated in the $1 \mathrm{kDa}$ retentate presents the same condensation degree as the internal MWL standard testifying about its low condensation state (0.66 and 0.67 respectively). In other words, a low level of carbon-carbon branching on the aromatic rings is reported in addition to the high aryl ether content observed.

Taken together, the data generated on the TMP lignin indicate its great potential for aromatic platform molecules production by depolymerisation. However, the high sugar and ash content of the $1 \mathrm{kDa}$ fraction may act as catalyst poisons for a great number a chemical processes. As $69 \%$ of this lignin is covalently linked to the hemicelluloses, further purification will be limited by really low recovery yields. On another hand, the presence of covalent linkages between GGM and lignin greatly improves the lignin water solubility and offers the possibility to design homogeneous catalysis processes in aqueous media, limiting the use of solvent. As the lignin solubility is one of the main impediments limiting its biological depolymerisation, LCCs may represent a more suitable candidate for biocatalysis. While considering biological depolymerisation, the LCC fraction can also be directly used as fermentation medium thanks to its high carbohydrate content reducing the overall cost of the process. 
Molar Mass Distribution. Size exclusion chromatograms of the initial $1 \mathrm{kDa}$ retentate and the supernatant and solid residue from hot water partition are presented in Figure 9. As can be seen at $280 \mathrm{~nm}$, the lignin recovered in the solid residue presents an apparent molecular weight (aMW) of $7 \mathrm{kDa}$ with a narrow weight distribution. LCCs recovered in the supernatant also present a maximum peak at $7 \mathrm{kDa}$ but are characterised by a slightly broader distribution with a shoulder around $4 \mathrm{kDa}$ (Figure 9A). The sum of the supernatant and solid residue chromatograms perfectly fits the one of the initial retentate indicating that no modification of the macromolecules aMW was driven by the extraction. The main signal detected by the RID detector in the initial retentate corresponds to an aMW of $3.5 \mathrm{kDa}$ (Figure 9B). This additional peak which is not detected by the UV detector is attributed to the GGM. Structural modification of those polysaccharides must occur during the hot water extraction as the $3.5 \mathrm{kDa}$ peak disappears in the supernatant. The sum of the supernatant and solid residue chromatograms differs from the initial retentate. This observation supports our previous hypothesis on partial deacetylation and denaturation of GGM. Hot water extraction is thus a suitable method for lignin quantification but structural changes of the initial macromolecules, both for lignin and hemicelluloses, should be considered while applying this protocol for separation and purification purposes. 


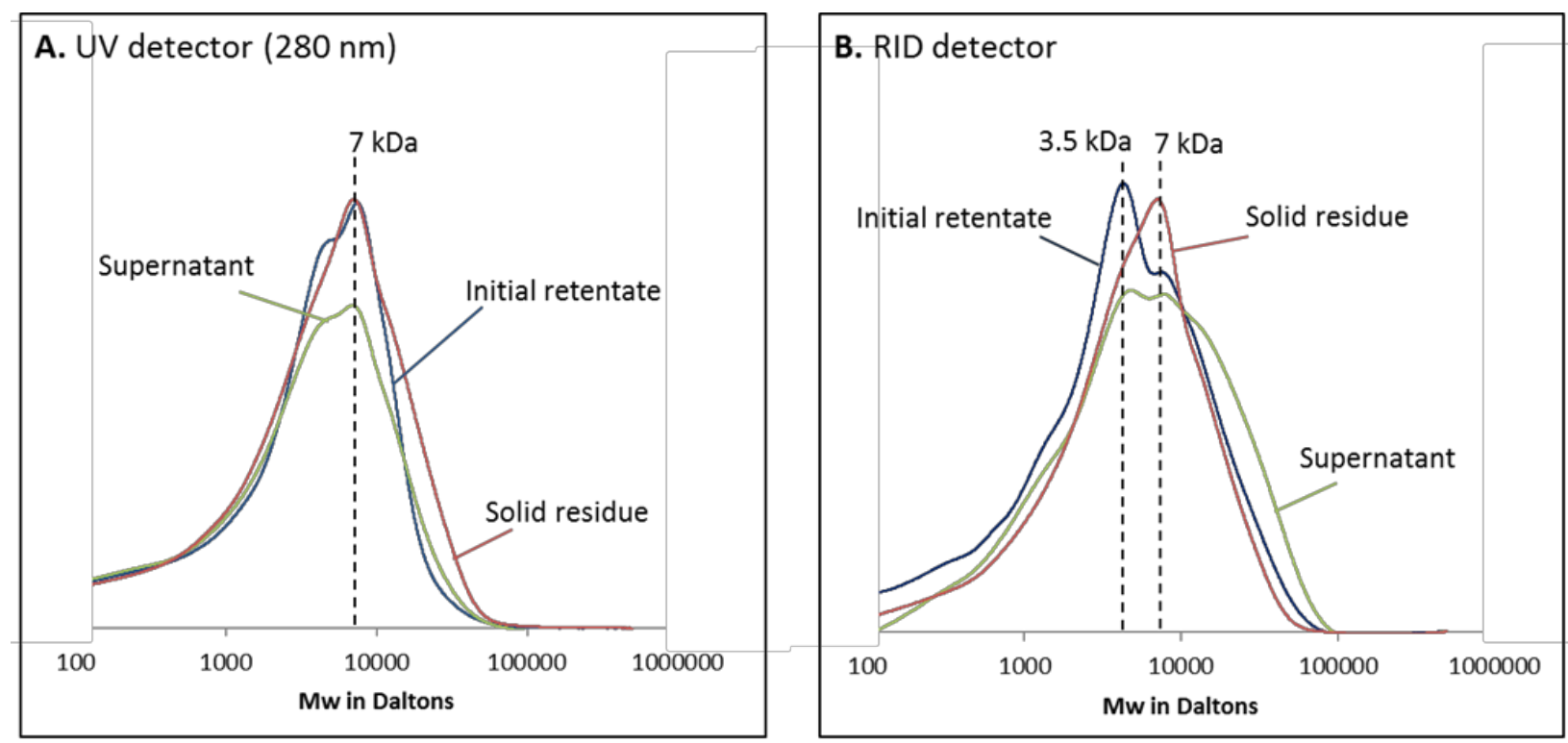

Figure 9. SEC chromatograms of the $1 \mathrm{kDa}$ retentate and the supernatant and solid residue from hot water solid-liquid extraction.

The membrane filtration process allowed the recovery of a specific fraction of macromolecules with a quite narrow range of aMW. This fact underlines the suitability of such process for the concentration and purification of the biomolecules along filtration. The aMW observed for lignin and GGM are in the lower range of existing values but are consistent with the literature. $5,11,12,39$ Their low molecular weights might be a limiting factor while considering biomaterial application. However, advantage of LCCs is that their polymerisation into HMW biopolymers can be enzymatically catalysed by laccases thanks to their aromatic units as described previously. ${ }^{5,21}$ This green process, in agreement with the bioeconomy philosophy, opens interesting LCCs valorisation pathways as renewable film forming macromolecules.

Concluding Discussion. This work generated valuable knowledge on all macromolecules that can be recovered from TMP biorefineries side stream for valorisation. A summary of the generated data is given in Table 3. 
Table 3. Summary of the compositional and structural characteristics of the three macromolecules recovered from TMP process water.

\begin{tabular}{|c|c|c|c|}
\hline & GGM & LCCs & Lignin \\
\hline $\begin{array}{l}\% \text { in TMP process } \\
\text { water }\end{array}$ & $35 \%$ & $40 \% *$ & $7 \%$ \\
\hline Water solubility & Soluble in hot water & Soluble in hot water & none \\
\hline $\begin{array}{l}\text { Structural } \\
\text { characteristics }\end{array}$ & $\begin{array}{c}\text { Man:Glc:Gal 3.1:1:0.6 } \\
\text { Partial acetylation of } \\
\text { mannose in } C_{2} \text { and } C_{3}\end{array}$ & $\begin{array}{l}\text { GGM and lignin } \\
\text { linked through phenyl } \\
\text { glycosidic bonds }\end{array}$ & $\begin{array}{c}\text { G units mainly linked } \\
\text { through } \beta-O-4 \text { linkages } \\
\text { Low condensation } \\
\text { degree }\end{array}$ \\
\hline $\begin{array}{l}\text { Apparent molecular } \\
\text { weight }\end{array}$ & $3.5 \mathrm{kDa}$ & 4-7 kDa & $7 \mathrm{kDa}$ \\
\hline
\end{tabular}

*Partly estimated on the basis of published data. ${ }^{5}$

An original approach was taken considering the presence of LCCs as a new type of macromolecule, independent from GGM and lignin. In this sense, this work differs from the actual literature on TMP process water valorisation. LCCs application for renewable material production in replacement to petroleum-based products will directly depend on their molecular mass, internal linkages and functionalization. A deep LCCs characterisation is reported in this paper including their chemical composition, molecular mass and chemical structure such as lignin carbohydrate and lignin interunit bonds and the condensation state of their lignin moieties. Additional information about their functionalisation and phenolic content could be interesting to better understand their reactivity and grafting potential. Different approaches have been reported, using either ionic liquid or enzymatic treatment, to allow their analysis by ${ }^{31} \mathrm{P}$ NMR despite their lack of solubility in classical solvent. ${ }^{13,39}$ 
Indirect methods were previously reported in the literature to decipher the presence of LCCs in TMP process water and their characterisation was achieved in this work using $2 \mathrm{D}$ HSQC and ${ }^{13} \mathrm{C}$ NMR. A quantitative analysis of the different LCC linkages provides tangible proofs of the mildness of the thermomechanical pulping. In this sense, the TMP process water represents an industrial feedstock of native wood structures. Those compounds can be recovered in substantial amount compared to lab-scale extractions and by mean of clean separation processes, such as membrane filtration, instead of using toxic solvent like dioxane. The native state of the macromolecules recoverable from the TMP process water renders their utilisation appealing even if they are really diluted in the side stream at the beginning and if TMP plants only represent a small part of the biorefinery market. Indeed, ongoing research currently utilizes various pretreatment methods to minimize LCCs as they represent a hindrance to efficient delignification. Their recovery from residual feedstock tends to be limited by such pretreatments making TMP process water a really interesting sourcing of unique macromolecules compared to other biorefineries.

In this work, the membrane filtration process employed allowed the recovery of a fraction enriched in one specific type of LCCs only composed of GGM linked to lignin through phenyl glycosidic bonds. Further purification steps could be considered to separate the GGM, lignin and LCCs co-concentrated in the fraction leading to the production of high quality model compounds. A simple and clean hot water extraction was successfully applied for the isolation of lignin in this work but small structural modifications were pointed out and need to be taken in account. The use of polymeric adsorbent resins with high specificity towards aromatics is also often reported in the literature. ${ }^{10,40}$ However, it's important to consider the environmental impact of such processes in their development by using, as much as possible, clean solvents for 
desorption and efficient resin regeneration methods. In another hand, the global recovered fraction can find direct application such as for the production of aromatic platform molecules by fungal depolymerisation or the production of interesting chemicals derived from the sugars by fermentation. ${ }^{41}$

The analytical data set, generated on this fraction produced at a pilote scale, demonstrates the interest of valorising TMP process water while considering the optimisation of TMP plant fluxes, profitability and environmental footprint. The results generated are expected to be close while operating at industrial scale thanks to the great scalability of the process. Direct implementation of industrial filtration units on site may be considered and the installation sizing can be adapted in order to fit the biorefinery fluxes and targeted market needs. A considerable advantage of the membrane process also rely in the fact that not only the LCC fraction valorisation is profitable but the other fractions generated present interesting adding values too. In that sense, the process cost will be amortised over all fractions and applications with lower added values such as biomaterial production can thus be considered. ${ }^{42}$

\section{ASSOCIATED CONTENT}

Supplemental experimental details on the membrane filtration process, elemental analysis and Pyro-GC-MS data of the $1 \mathrm{kDa}$ retentate as well as the 2D-HSQC and 13C NMR signals assignments are available as Supporting Information (PDF).

\section{AUTHOR INFORMATION}

\section{Corresponding Author}

* Corresponding author email: maud.villain@unistra.fr, tel: +33(0)368852748 


\section{Author Contributions}

The manuscript was written through contributions of all authors. All authors have given approval to the final version of the manuscript.

\section{Note}

The authors declare no competing financial interest.

\section{ACKNOWLEDGMENT}

The NMR platform team form the Institut Jean Barriol, and in particular Mrs Sophie Poinsignon, is gratefully acknowledged for its technical support and contribution on the lignin characterisation work.

\section{REFERENCES}

(1) Sundholm, J. Mechanical Pulping, Gummers Printing.; Papermaking Science and Technology Series; Finnish Paper Engineers' Association and TAPPI: Jyväskylä, Finland, 1999.

(2) Zasadowski, D.; Strand, A.; Sundberg, A.; Edlund, H.; Norgren, M. Selective Purification of Bleached Spruce TMP Process Water by Induced Air Flotation (IAF). Holzforschung 2014, 68 (2), 157-165. https://doi.org/10.1515/hf-2013-0045.

(3) Persson, T.; Nordin, A.-K.; Zacchi, G.; Jönsson, A.-S. Economic Evaluation of Isolation of Hemicelluloses from Process Streams from Thermomechanical Pulping of Spruce. Appl. Biochem. Biotechnol. 2007, 136, 741-752.

(4) Krawczyk, H.; Oinonen, P.; Jönsson, A.-S. Combined Membrane Filtration and Enzymatic Treatment for Recovery of High Molecular Mass Hemicelluloses from Chemithermomechanical Pulp Process Water. Chem. Eng. J. 2013, 225, 292-299. https://doi.org/10.1016/j.cej.2013.03.089. 
(5) Oinonen, P.; Areskogh, D.; Henriksson, G. Enzyme Catalyzed Cross-Linking of Spruce Galactoglucomannan Improves Its Applicability in Barrier Films. Carbohydr. Polym. 2013, 95 (2), 690-696. https://doi.org/10.1016/j.carbpol.2013.03.016.

(6) Persson, T.; Krawczyk, H.; Nordin, A.-K.; Jönsson, A.-S. Fractionation of Process Water in Thermomechanical Pulp Mills. Bioresour. Technol. 2010, 101 (11), 3884-3892. https://doi.org/10.1016/j.biortech.2009.12.142.

(7) Persson, T.; Jönsson, A.-S. Isolation of Hemicelluloses by Ultrafiltration of Thermomechanical Pulp Mill Process Water-Influence of Operating Conditions. Chem. Eng. Res. Des. 2010, 88 (12), 1548-1554. https://doi.org/10.1016/j.cherd.2010.04.002.

(8) Puro, L.; Kallioinen, M.; Mänttäri, M.; Natarajan, G.; C. Cameron, D.; Nyström, M. Performance of RC and PES Ultrafiltration Membranes in Filtration of Pulp Mill Process Waters. Desalination 2010, 264 (3), 249-255. https://doi.org/10.1016/j.desal.2010.06.034.

(9) Willför, S.; Sjöholm, R.; Laine, C.; Roslund, M.; Hemming, J.; Holmbom, B. Characterisation of Water-Soluble Galactoglucomannans from Norway Spruce Wood and Thermomechanical Pulp. Carbohydr. Polym. 2003, 52 (2), 175-187. https://doi.org/10.1016/S0144-8617(02)00288-6.

(10) Pranovich, A. V.; Reunanen, M.; Sjöholm, R.; Holmbom, B. Dissolved Lignin and Other Aromatic Substances in Thermomechanical Pulp Waters. J. Wood Chem. Technol. 2005, 25 (3), 109-132. https://doi.org/10.1080/02773810500191575.

(11) Krawczyk, H.; Jönsson, A.-S. Separation of Dispersed Substances and Galactoglucomannan in Thermomechanical Pulp Process Water by Microfiltration. Sep. Purif. Technol. 2011, 79 (1), 4349. https://doi.org/10.1016/j.seppur.2011.03.009.

(12) Thuvander, J.; Jönsson, A.-S. Extraction of Galactoglucomannan from Thermomechanical Pulp Mill Process Water by Microfiltration and Ultrafiltration-Influence of Microfiltration Membrane Pore Size on Ultrafiltration Performance. Chem. Eng. Res. Des. 2016, 105, 171-176. https://doi.org/10.1016/j.cherd.2015.12.003.

(13) Lawoko, M. Unveiling the Structure and Ultrastructure of Lignin Carbohydrate Complexes in Softwoods. Int. J. Biol. Macromol. 2013, 62, 705-713. https://doi.org/10.1016/j.ijbiomac.2013.10.022.

(14) Lawoko, M.; Henriksson, G.; Gellerstedt, G. Characterisation of Lignin-Carbohydrate Complexes (LCCS) of Spruce Wood (Picea Abies L.) Isolated with Two Methods. Holzforschung 2006, 60 (2), 156-161. https://doi.org/10.1515/HF.2006.025. 
(15) Giummarella, N.; Zhang, L.; Henriksson, G.; Lawoko, M. Structural Features of Mildly Fractionated Lignin Carbohydrate Complexes (LCC) from Spruce. RSC Adv. 2016, 6 (48), 42120-42131. https://doi.org/10.1039/C6RA02399A.

(16) Balakshin, M.; Capanema, E.; Gracz, H.; Chang, H.; Jameel, H. Quantification of LigninCarbohydrate Linkages with High-Resolution NMR Spectroscopy. Planta 2011, 233 (6), 10971110. https://doi.org/10.1007/s00425-011-1359-2.

(17) Yuan, T.-Q.; Sun, S.-N.; Xu, F.; Sun, R.-C. Characterization of Lignin Structures and LigninCarbohydrate Complex (LCC) Linkages by Quantitative 13C and 2D HSQC NMR Spectroscopy. J. Agric. Food Chem. 2011, 59 (19), 10604-10614. https://doi.org/10.1021/jf2031549.

(18) You, T.-T.; Zhang, L.-M.; Zhou, S.-K.; Xu, F. Structural Elucidation of Lignin-Carbohydrate Complex (LCC) Preparations and Lignin from Arundo Donax Linn. Ind. Crops Prod. 2015, 71, 65-74. https://doi.org/10.1016/j.indcrop.2015.03.070.

(19) Lawoko, M.; Henriksson, G.; Gellerstedt, G. Structural Differences between the Lignin-Carbohydrate Complexes Present in Wood and in Chemical Pulps. Biomacromolecules 2005, 6 (6), 3467-3473. https://doi.org/10.1021/bm058014q.

(20) Zhao, H.; Li, J.; Wang, P.; Zeng, S.; Xie, Y. Lignin-Carbohydrate Complexes Based Spherical Biocarriers: Preparation, Characterization, and Biocompatibility https://www.hindawi.com/journals/ijps/2017/4915185/ (accessed Nov 13, 2018). https://doi.org/10.1155/2017/4915185.

(21) Oinonen, P.; Krawczyk, H.; Ek, M.; Henriksson, G.; Moriana, R. Bioinspired Composites from CrossLinked Galactoglucomannan and Microfibrillated Cellulose: Thermal, Mechanical and Oxygen Barrier Properties. Carbohydr. Polym. 2016, 136, 146-153.

https://doi.org/10.1016/j.carbpol.2015.09.038.

(22) Sakagami, H.; Kushida, T.; Oizumi, T.; Nakashima, H.; Makino, T. Distribution of LigninCarbohydrate Complex in Plant Kingdom and Its Functionality as Alternative Medicine. Pharmacol. Ther. 2010, 128 (1), 91-105. https://doi.org/10.1016/j.pharmthera.2010.05.004.

(23) Zhang, Y.; But, P. P.-H.; Ooi, V. E.-C.; Xu, H.-X.; Delaney, G. D.; Lee, S. H. S.; Lee, S. F. Chemical Properties, Mode of Action, and in Vivo Anti-Herpes Activities of a Lignin-Carbohydrate Complex from Prunella Vulgaris. Antiviral Res. 2007, 75 (3), 242-249.

https://doi.org/10.1016/j.antiviral.2007.03.010. 
(24) Sakagami, H.; Sheng, H.; Okudaira, N.; Yasui, T.; Wakabayashi, H.; Jia, J.; Natori, T.; SuguroKitajima, M.; Oizumi, H.; Oizumi, T. Prominent Anti-UV Activity and Possible Cosmetic Potential of Lignin-Carbohydrate Complex. In Vivo 2016, 30 (4), 331-339.

(25) Narron, R. H.; Chang, H.; Jameel, H.; Park, S. Soluble Lignin Recovered from Biorefinery Pretreatment Hydrolyzate Characterized by Lignin-Carbohydrate Complexes. ACS Sustain. Chem. Eng. 2017, 5 (11), 10763-10771. https://doi.org/10.1021/acssuschemeng.7b02716.

(26) Al-Rudainy, B.; Galbe, M.; Wallberg, O. Influence of Prefiltration on Membrane Performance during Isolation of Lignin-Carbohydrate Complexes from Spent Sulfite Liquor. Sep. Purif. Technol. 2017, 187, 380-388. https://doi.org/10.1016/j.seppur.2017.06.031.

(27) Brosse, N.; El Hage, R.; Chaouch, M.; Pétrissans, M.; Dumarçay, S.; Gérardin, P. Investigation of the Chemical Modifications of Beech Wood Lignin during Heat Treatment. Polym. Degrad. Stab. 2010, 95 (9), 1721-1726. https://doi.org/10.1016/j.polymdegradstab.2010.05.018.

(28) Holtman, K. M.; Chang, H.; Jameel, H.; Kadla, J. F. Quantitative ${ }^{13}$ C NMR Characterization of Milled Wood Lignins Isolated by Different Milling Techniques. J. Wood Chem. Technol. 2006, 26 (1), 21-34. https://doi.org/10.1080/02773810600582152.

(29) Ross, N. W.; Johnson, K. G.; Roger, C. Enzymic Hydrolysis of Water-Soluble Lignin-Carbohydrate Complexes from Populus Deltoides: Effects of , Combinations of P-Mannanases, Xylanase, and Acetyl Xylan Esterase. Enzyme Microb. Technol. 1992, 14, 90-95.

(30) Willför, S.; Sundberg, K.; Tenkanen, M.; Holmbom, B. Spruce-Derived Mannans - A Potential Raw Material for Hydrocolloids and Novel Advanced Natural Materials. Carbohydr. Polym. 2008, 72 (2), 197-210. https://doi.org/10.1016/j.carbpol.2007.08.006.

(31) Naron, D. R.; Collard, F.-X.; Tyhoda, L.; Görgens, J. F. Characterisation of Lignins from Different Sources by Appropriate Analytical Methods: Introducing Thermogravimetric Analysis-Thermal Desorption-Gas Chromatography-Mass Spectroscopy. Ind. Crops Prod. 2017, 101, 61-74. https://doi.org/10.1016/j.indcrop.2017.02.041.

(32) Pandey, K. .; Pitman, A. . FTIR Studies of the Changes in Wood Chemistry Following Decay by Brown-Rot and White-Rot Fungi. Int. Biodeterior. Biodegrad. 2003, 52 (3), 151-160. https://doi.org/10.1016/S0964-8305(03)00052-0.

(33) Dehne, L.; Vila Babarro, C.; Saake, B.; Schwarz, K. U. Influence of Lignin Source and Esterification on Properties of Lignin-Polyethylene Blends. Ind. Crops Prod. 2016, 86, 320-328. https://doi.org/10.1016/j.indcrop.2016.04.005. 
(34) Ding, R.; Wu, H.; Thunga, M.; Bowler, N.; Kessler, M. R. Processing and Characterization of LowCost Electrospun Carbon Fibers from Organosolv Lignin/Polyacrylonitrile Blends. Carbon 2016, 100, 126-136. https://doi.org/10.1016/j.carbon.2015.12.078.

(35) Laine, C.; Tamminen, T.; Hortling, B. Carbohydrate Structures in Residual Lignin-Carbohydrate Complexes of Spruce and Pine Pulp. Holzforschung 2004, 58 (6), 611-621. https://doi.org/10.1515/HF.2004.115.

(36) Persson, T.; Jönsson, A.-S. Characterization of Hemicelluloses in Process Streams in Thermomechanical and Chemi-Thermomechanical Pulp Mills. J. Wood Chem. Technol. 2017, 37 (3), 184-190. https://doi.org/10.1080/02773813.2016.1271433.

(37) Constant, S.; Wienk, H. L. J.; Frissen, A. E.; Peinder, P. de; Boelens, R.; van Es, D. S.; Grisel, R. J. H.; Weckhuysen, B. M.; Huijgen, W. J. J.; Gosselink, R. J. A.; et al. New Insights into the Structure and Composition of Technical Lignins: A Comparative Characterisation Study. Green Chem. 2016, 18 (9), 2651-2665. https://doi.org/10.1039/C5GC03043A.

(38) Giummarella, N.; Lawoko, M. Structural Insights on Recalcitrance during Hydrothermal Hemicellulose Extraction from Wood. ACS Sustain. Chem. Eng. 2017, 5 (6), 5156-5165. https://doi.org/10.1021/acssuschemeng.7b00511.

(39) Oinonen, P.; Zhang, L.; Lawoko, M.; Henriksson, G. On the Formation of Lignin Polysaccharide Networks in Norway Spruce. Phytochemistry 2015, 111, 177-184.

https://doi.org/10.1016/j.phytochem.2014.10.027.

(40) Westerberg, N.; Sunner, H.; Helander, M.; Henriksson, G.; Lawoko, M.; Rasmuson, A. Separation of galactoglucomannans, lignin, and lignin-carbohydrate complexes from hot-water-extracted norway spruce by cross-flow filtration and adsorption chromatography. BioResources 2012, 7 (4), 4501-4516. https://doi.org/10.15376/biores.7.4.4501-4516.

(41) Saratale, G. D.; Jung, M.-Y.; Oh, M.-K. Reutilization of Green Liquor Chemicals for Pretreatment of Whole Rice Waste Biomass and Its Application to 2,3-Butanediol Production. Bioresour. Technol. 2016, 205, 90-96. https://doi.org/10.1016/j.biortech.2016.01.028.

(42) Ho, H. C.; Goswami, M.; Chen, J.; Keum, J. K.; Naskar, A. K. Amending the Structure of Renewable Carbon from Biorefinery Waste-Streams for Energy Storage Applications. Sci. Rep. 2018, 8 (1), 8355-8367. https://doi.org/10.1038/s41598-018-25880-0. 


\section{TABLE OF CONTENTS GRAPHIC}

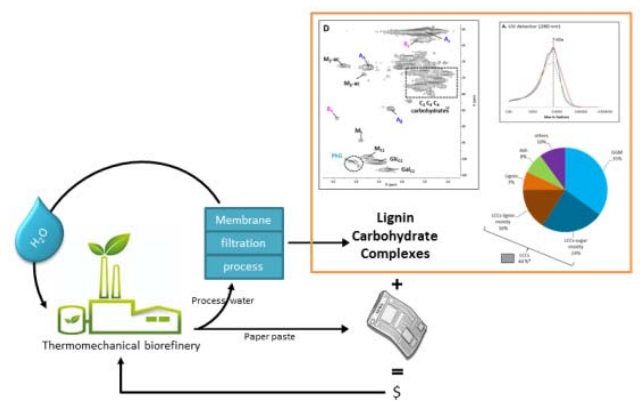

SYNOPSIS: An industrial sourcing of LCCs recovered by a membrane filtration process from the residual feedstock of a TMP plant is reported. 